\title{
Global Scenarios for Carbon Dioxide Emissions $\uparrow$
}

\author{
Alan S. Manneł and Leo Schrattenholzer§, \\ †Dept. of Operations Research, Stanford University, Stanford, CA 94305, USA \\ §IIASA, A-2361 Laxenburg, Austria
}

(Received 1 June 1993)

Abstract - The status of global greenhouse-gas emissions is summarized as of December 1992.

\section{The CHALLENGE Network}

CHALLENGE $\|$ is a network of researchers exploring globally efficient measures to reduce the risk of adverse climate change. The network consists of research groups working with national or regional scenarios of greenhouse gases (GHG) emissions. Its focal nodes are the University of Stuttgart, Stanford University, and IIASA. This report describes the status of the project's activities as of the Fifth CHALLENGE Symposium held at IIASA from 3-4 December 1992.

To date, the results produced during network activities include reference scenarios of energy-related carbon emissions in countries and regions with high emissions: the USA, the former USSR, and China. These were used as the basis for the formulation of Reference scenarios with the Global 2100 model. In turn, this model was used for the investigation of GHG reduction scenarios. This paper summarizes the results of the country studies and describes the controlled comparisons resulting from the Global 2100 model. The readers interested in details of national GHG emissions scenarios are referred to the reports that were distributed at the December 1992 CHALLENGE meeting.

For a recent description of International Energy Workshop (IEW) activities, see Manne et al. ${ }^{1}$

\subsection{The CHALLENGE Poll}

To compare projections in a standard format, we employed the poll form shown in Table 1. Readers familiar with the IEW ${ }^{1}$ will recognize similarities with the IEW poll form. The principal difference is that there are two additional rows. One reports total carbon emissions, and the other describes the marginal costs associated with the maximum reduction costs in a specific reduction scenario. This final row indicates the cut-off point (expressed in US dollars per ton of carbon) for the costs of the supply and conservation responses considered in this scenario.

IAuthor for correspondence from whom copies of meeting papers may be obtained.

\|This acronym, Common House ALternatives on Long-term ENergy Strategies under Global Environmental Concern, reflects the original European focus of the project. 
Table 1. CHALLENGE poll form to obtain scenario results.

Please do not make changes to the definitions indicated here. Leave out a number rather than making major changes to the items described here. Minor changes (such as "includes bunkers") can be formulated as footnotes. Ranges should be replaced by midpoints. Alternatively, more than one scenario may be submitted for a given region (on separate forms). Please TYPE your response!

Country/Region/Scenario name:

Organization/Project:

Reference (including date) of most recent report:

\begin{tabular}{|c|c|c|c|c|}
\hline & 1990 & 2000 & 2010 & 2020 \\
\hline $\begin{array}{l}\text { 1. International price of crude oil, } \\
\text { e.g., Arabian Light (US } \$(' 90) / \mathrm{bbl} \text { ) } \\
\text { 2. Real GNP (or GDP) } \\
\text { Units: Index numbers, constant } \\
\text { purchasing power, } 1990=100\end{array}$ & 100 & & & \\
\hline $\begin{array}{l}\text { Primary energy, commercial, } \\
\text { million tons of oil equivalent (mtoe) } \\
\text { 3. Total consumption } \\
\text { 4. Total production } \\
\end{array}$ & & & & \\
\hline $\begin{array}{l}\text { 5. Oil, consumption } \\
\text { 6. Oil, production } \\
\text { 7. Oil, exports }- \text { imports }^{\mathrm{a}}\end{array}$ & & & & \\
\hline $\begin{array}{l}\text { 8. Natural gas, consumption } \\
\text { 9. Natural gas, production } \\
\text { 10. Natural gas, exports - imports }\end{array}$ & & & & \\
\hline $\begin{array}{l}\text { 11. Coal, consumption } \\
\text { 12. Coal, production } \\
\text { b } \\
\text { 13. Coal, exports - imports } \\
\end{array}$ & & & & \\
\hline $\begin{array}{l}\text { 14. Renewables, electric }{ }^{c} \\
\text { 15. Nuclear energy } \\
\text { 16. Renewables, nonelectric }\end{array}$ & & & & \\
\hline $\begin{array}{l}\text { Secondary energy, terawatthours (TWh) } \\
\text { 17. Total electricity generation }\end{array}$ & & & & \\
\hline $\begin{array}{l}\text { 18. } \mathrm{CO}_{2} \text { emissions, } 10^{6} \text { tons of carbon (tc) } \\
\text { 19. Marginal costs of carbon emission reduction } \\
(\mathrm{US} \$(90) / \mathrm{tc})\end{array}$ & & & & \\
\hline
\end{tabular}

- Oil includes natural gas liquids, unconventional oils and synthetics based on tar sands and shale oil.

${ }^{b} \mathrm{Coal}$ includes solid fuels such as lignite and peat and also coal consumed for the manufacture of synthetic fuels.

'Primary substitution equivalent; includes hydro, geothermal, etc. 


\subsection{Poll Results}

For purposes of analysis based on the Global 2100 model, the CHALLENGE poll results have been grouped into the following regions: (i) Eastern Europe and Former Soviet Union (EEFSU), (ii) China, (iii) USA, (iv) Other OECD countries (OOECD), (v) Rest of the World (ROW). We summarize the CHALLENGE poll results in terms of median growth rates. In this way, we give equal weight to all poll responses for each of these regions or its subregions. This procedure provides satisfactory Reference scenarios for those regions that consist of a single country: China and USA. Likewise, the poll results for the OOECD region were aggregated without major problems. In contrast, the EEFSU projections presented special difficulties. From the responses, it became clear that there were unanticipated difficulties in the transition from planned to market economies within this region. The uncertainties of any projections are particularly high for this region, both for the CHALLENGE poll responses and for the Global 2100 model runs. We therefore performed a special sensitivity analysis for EEFSU to reflect the wide range of developments that seem to be possible there.

The ROW (Rest of the World) region includes a great variety of a large number of countries. Specific CHALLENGE poll responses are available for only about $40 \%$ of energy-related carbon emissions in this region. We did, however, have the benefit of responses covering two major subregions. One was provided by OLADE for Latin America and the Caribbean. Another was provided by OPEC for the OPEC countries as a whole. Because of the limited coverage of the CHALLENGE poll, we adopted most of the original global 2100 numerical inputs ${ }^{2}$ for the ROW region.

\section{Reference Scenarios}

For purposes of the Reference scenarios, perhaps the key indicators are the growth rates of three region-specific variables: economic output, total primary energy consumption, and carbon emissions. For each country or region, these growth rates describe the expected development of the energy intensity of an economy and the decarbonization of its energy system. Figure 1 shows the medians for the three indicators, taken from all responses to the CHALLENGE poll.

Figure 1 shows that the median expectations include a decrease of total commercial primary energy consumption per unit of GDP and, to a lesser extent, a decarbonization of primary energy supplies. The most pronounced decline of energy intensity occurs in EEFSU and OOECD.

To show the expected developments of energy intensity and decarbonization, we calculate index numbers with 1990 as the base year, and estimate the rangest of all Reference cases, that is for all countries and regions together in Figs. 2 and 3. In 2020, the median of the energy intensity indices is just under $70 \%$ of the 1990 value. This result is equivalent to an average annual decline rate of $1.23 \%$. The median carbonization in 2020 is approximately $7 \%$ compared to 1990 , and the average annual decline rate is $0.24 \%$. In 2020 , the ranges cover the interval from $53 \%$ to $91 \%$ (the energy intensity is given in Fig.2) and from $74 \%$ to $107 \%$ (the carbon intensity is given in Fig.3).

tThe ranges are defined as intervals two sample variances wide and centered around the mean under the assumption of a $\log$-normal distribution. 


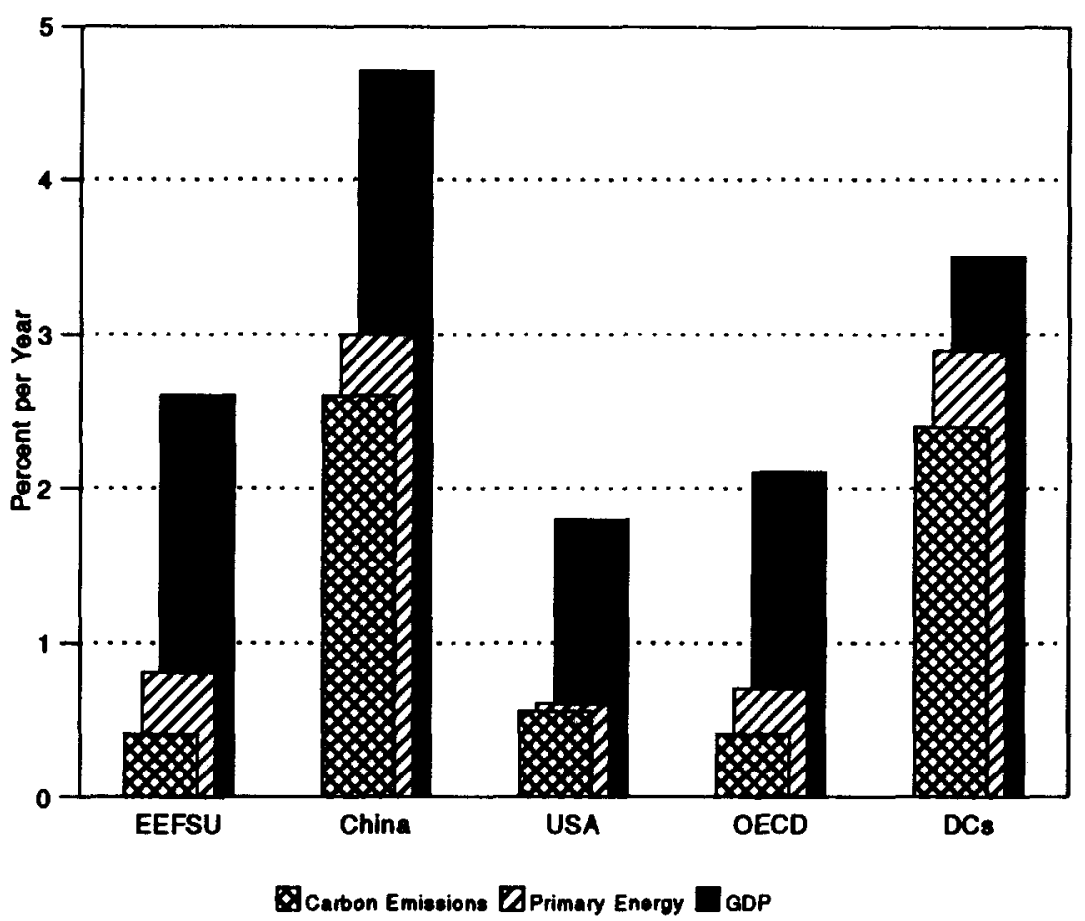

Figure 1. CHALLENGE results for the average annual percent growth rates between 1990 and 2020; carbon emissions, total primary energy consumption, and GDP.

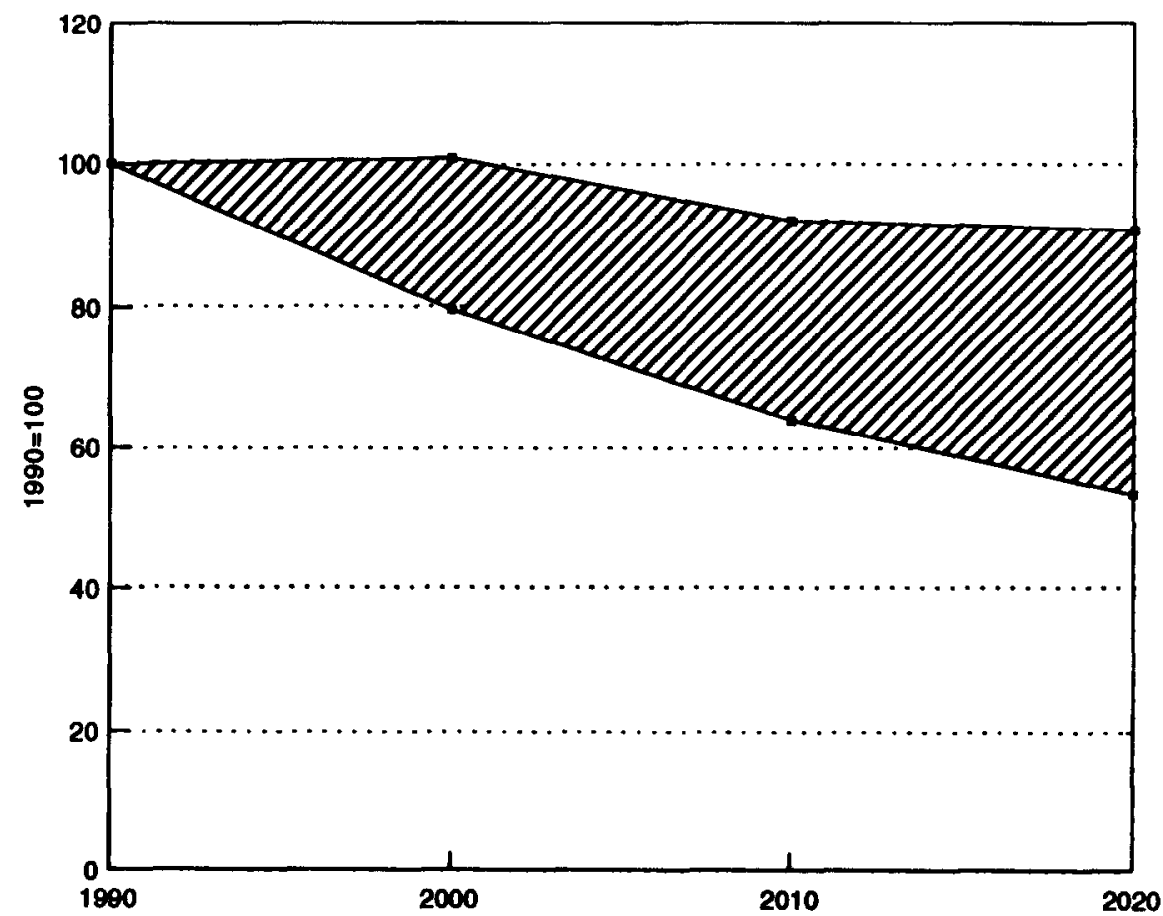

Figure 2. Ranges of primary energy intensity for all CHALLENGE Reference cases; the index numbers refer to 1990 as 100 . 


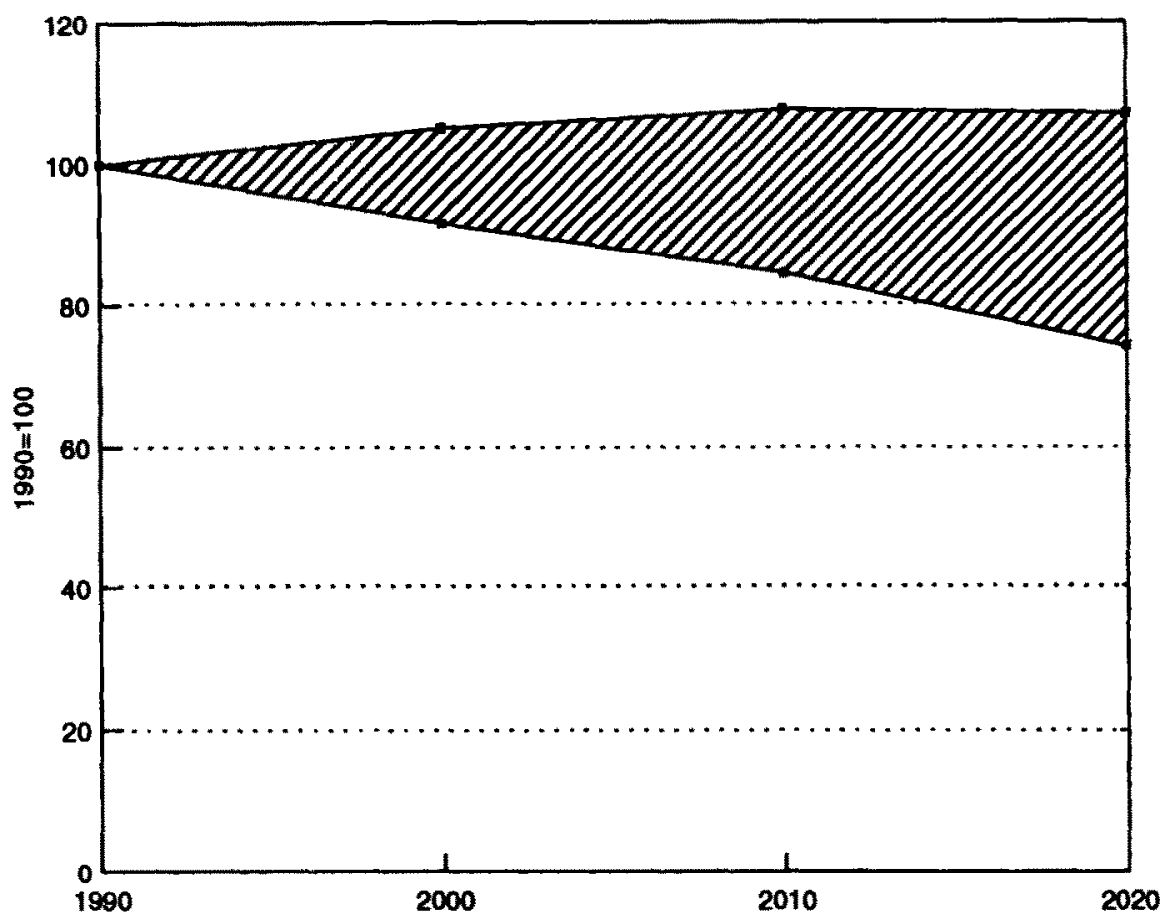

Figure 3. Ranges of carbon intensity of primary consumption for all CHALLENGE Reference cases; the index numbers refer to 1990 as 100 .

\section{Reduction Scenarios}

Prior to the CHALLENGE meeting of December 1992, the network participants had agreed on several classes of scenarios. In addition to the Reference case, there was a "controlled experiment" to identify the effect of implementing all those supply and conservation measures that would be cost-effective at values up to US\$200 per ton of carbon. In principle, these measures were to be superimposed over a "do nothing" scenario. This definition is logically equivalent to the imposition of a carbon tax of $\$ 200$ and domestic lump-sum recycling of the revenues generated by this tax.

Figure 4 summarizes the $\$ 200$ scenario. It shows the range of reductions in carbon emissions relative to the Reference scenario in which no specific abatement measures are taken. For the year 2020 , the median emissions in the $\$ 200$ scenario lie about one-third below those of the corresponding Reference case. At a global level, this would lead to the stabilization of total carbon emissions between 1990 and 2020 .

At this point (early 1993), there are controlled comparisons (between a Reference case and a $\$ 200$ scenario) available for only 16 countries or regions. Figure 4 provides only a rough indication of the shape of national cost-of-abatement curves. At a given cost, it shows that the optimal percentage reductions could vary significantly from country to country. This suggests that an internationally uniform percentage cut cannot be an economically efficient policy. 


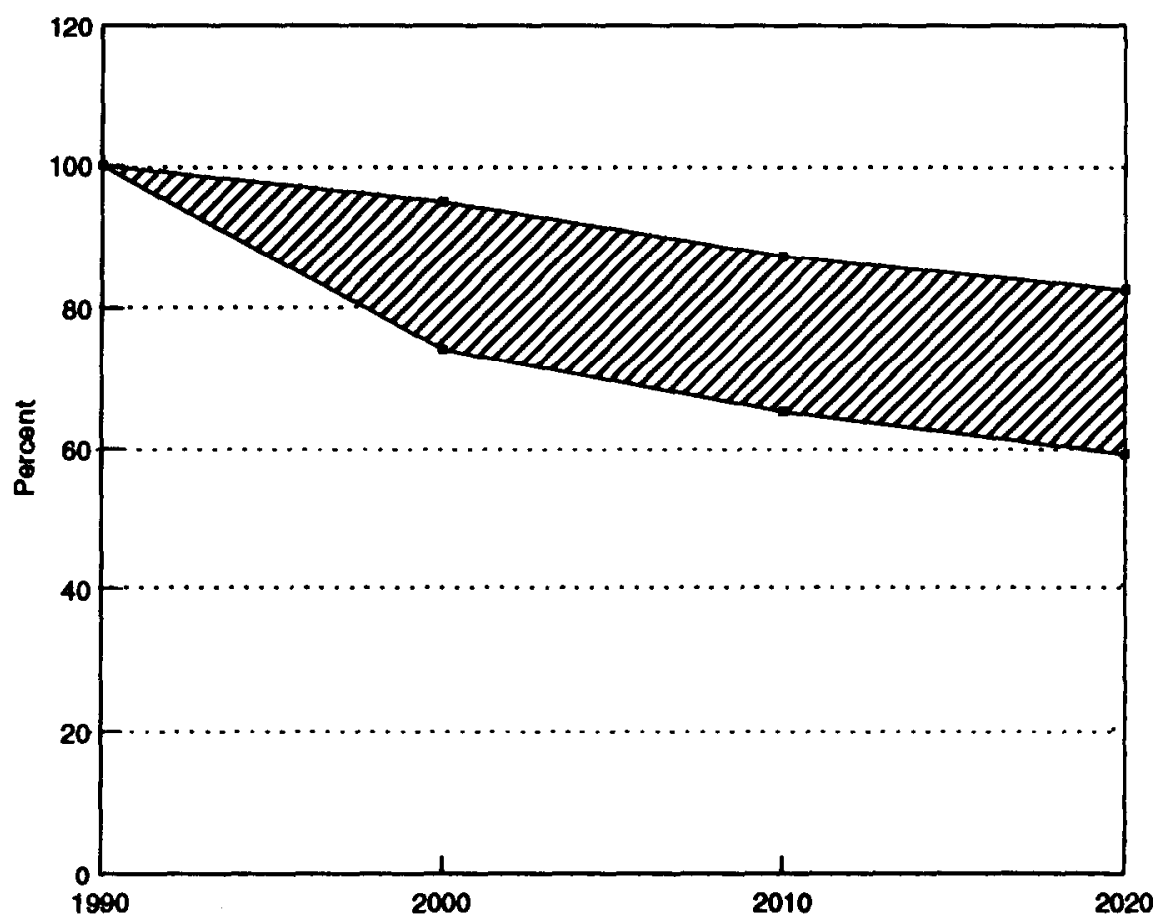

Figure 4. Ranges of carbon emission reductions in percent (relative to Reference cases) in CHALLENGE scenarios that include a $\$ 200 /$ ton carbon tax.

\section{Global 2100}

Global 2100 is a model of $\mathrm{CO}_{2}$-energy-economy interactions. For a description, see Manne and Richels. ${ }^{2}$ Global 2100 is intended to simulate either a market or a planned economy through a dynamic nonlinear optimization model. The objective function is the total discounted utility of a single representative producer-consumer. The maximization of this utility function determines a sequence of optimal savings, investment and consumption decisions. In turn, savings and investment determine the capital stock. Together with labor productivity and with energy inputs, this determines the total output of an economy according to the following nested CES (constant elasticity of substitution) production function:

$$
\mathrm{Y}_{\mathrm{t}}=\left[\mathrm{a}\left(\mathrm{K}_{\mathrm{t}}\right)^{\rho \alpha}\left(\mathrm{L}_{\mathrm{t}}\right)^{\rho(1-\alpha)}+\mathrm{b}\left(\mathrm{E}_{\mathrm{t}}\right)^{\rho \beta}\left(\mathrm{N}_{\mathrm{t}}\right)^{\rho(1-\beta)}\right]^{1 / \rho}, \quad(\mathrm{t}=1, \ldots \mathrm{T})
$$

where $Y_{t}=$ output at time $t, K_{t}=$ capital stock at time $t, L_{t}=$ labor force at time $t$, $E_{t}=$ demand for electric energy at time $t$ (before the AEEI is taken into account), $\alpha=$ optimal share of capital in the capital-labor aggregate; $\beta=$ optimal share of electricity in the energy aggregate, $\rho=1-(1 / \sigma)$ (with $\sigma=$ elasticity of substitution between the energy and the capital-labor aggregates), a,b = parameters estimated from base-year values. This function summarizes the interactions between the four primary factors of production: capital, labor, electricity, and non-electric energy. It has five parameters. Of these, only two $[\alpha$ and $\beta$, respectively the optimal value shares of capital (in the capital-labor aggregate) and electricity (in the electric-nonelectric energy aggregate)] are directly observable from base year data. The elasticity of substitution, $\sigma$, must be estimated through an indirect technique, e.g., the "backcasting" experiment described 
Table 2. Potential annual percentages of GDP growth rates given as average values for the 10-year period beginning on the date given; these are CHALLENGEderived inputs into Global 2100.

\begin{tabular}{l|c|c|c|c|c}
\hline $\begin{array}{l}\text { Decade } \\
\text { beginning in }\end{array}$ & USA & OOECD & EEFSU & China & ROW \\
\hline 1990 & 2.5 & 2.5 & 2.5 & 5.0 & 4.0 \\
2000 & 2.0 & 2.0 & 2.0 & 4.5 & 3.75 \\
2010 & 2.0 & 2.0 & 2.0 & 4.5 & 3.5 \\
2020 & 1.75 & 1.75 & 1.75 & 4.25 & 3.3 \\
\hline
\end{tabular}

in Chapter 9 of Manne and Richels. ${ }^{2}$ The two remaining parameters ( $a$ and $b$ ) are calculated from the production function in the base year and by supposing that the "reference price" of nonelectric energy represents its first partial derivative with respect to this input factor. The nested CES production function is linearly homogeneous, i.e., doubling (or any other increase by the same factor) of the inputs results in a doubling (or a corresponding increase) of the output. The optimal physical shares of the four productive factors depend on their relative prices and on the elasticity of substitution. In the short run, price responsiveness is limited by a "putty-clay" model. That is, the specific energy consumption by the existing capital stock is fixed. Price-induced conservation is associated specifically with the increments in the economy's capital stock.

In addition to price-induced conservation, the model allows for non-price long-term trends. These are described by an Autonomous Energy Efficiency Improvement (AEEI) parameter. This defines the annual rate of decoupling between GDP and energy demands, over and above the effect of price increases.

Labor productivity growth is a key input. The corresponding annual growth rates determine overall economic growth except for the effects of adjustments due to changes of the relative prices of the four primary factors of production. In the results reported here, the consequences are that the actual GDP growth rate is always within half a percentage point of the specified rate of labor and productivity growth. This holds true even for the carbon emission reduction scenarios.

As stated previously, the model has been applied in parallel for each of five regions: China, Eastern Europe and Former Soviet Union (EEFSU), USA, Other OECD countries (OOECD), and Rest of the World (ROW). The original model covered the time period from 1990 through 2100. The runs presented here are restricted to a horizon of 2050 . Because of the structure of the CHALLENGE poll, results are reported only through 2020 .

\subsection{The CHALLENGE Reference Scenario (Conventional Wisdom)}

Our Reference scenario is based on Manne and Richels (M-R), ${ }^{2}$ but the the M-R parameters have been modified so as to be consistent with the results reported by national study groups participating in the CHALLENGE project. Table 2 presents the potential macroeconomic rates assumed for the five regions. By comparison with the original inputs, the CHALLENGE poll suggests a slightly lower GDP growth in the OOECD and a slightly higher GDP growth in the ROW region.

Table 3 shows the other important determinant of actual energy demand, the AEEI factor. It is assumed that the AEEI coefficients are not identical in all regions and time periods. By comparison with the original $M-R$ inputs, we see here a minor increase of 
Table 3. Autonomous energy efficiency improvement (AEEI) given as percent per year for CHALLENGE-derived inputs into Global 2100.

\begin{tabular}{l|c|c|c|c|c}
\hline $\begin{array}{l}\text { Decade } \\
\text { beginning in }\end{array}$ & USA & OOECD & EEFSU & China & ROW \\
\hline 1990 & 0.5 & 0.7 & 0.5 & 0.5 & 0.0 \\
2000 & 0.5 & 0.7 & 0.5 & 0.5 & 0.0 \\
2010 & 0.5 & 0.7 & 0.5 & 0.5 & 0.1 \\
2020 & 0.5 & 0.7 & 0.5 & 0.5 & 0.2 \\
\hline
\end{tabular}

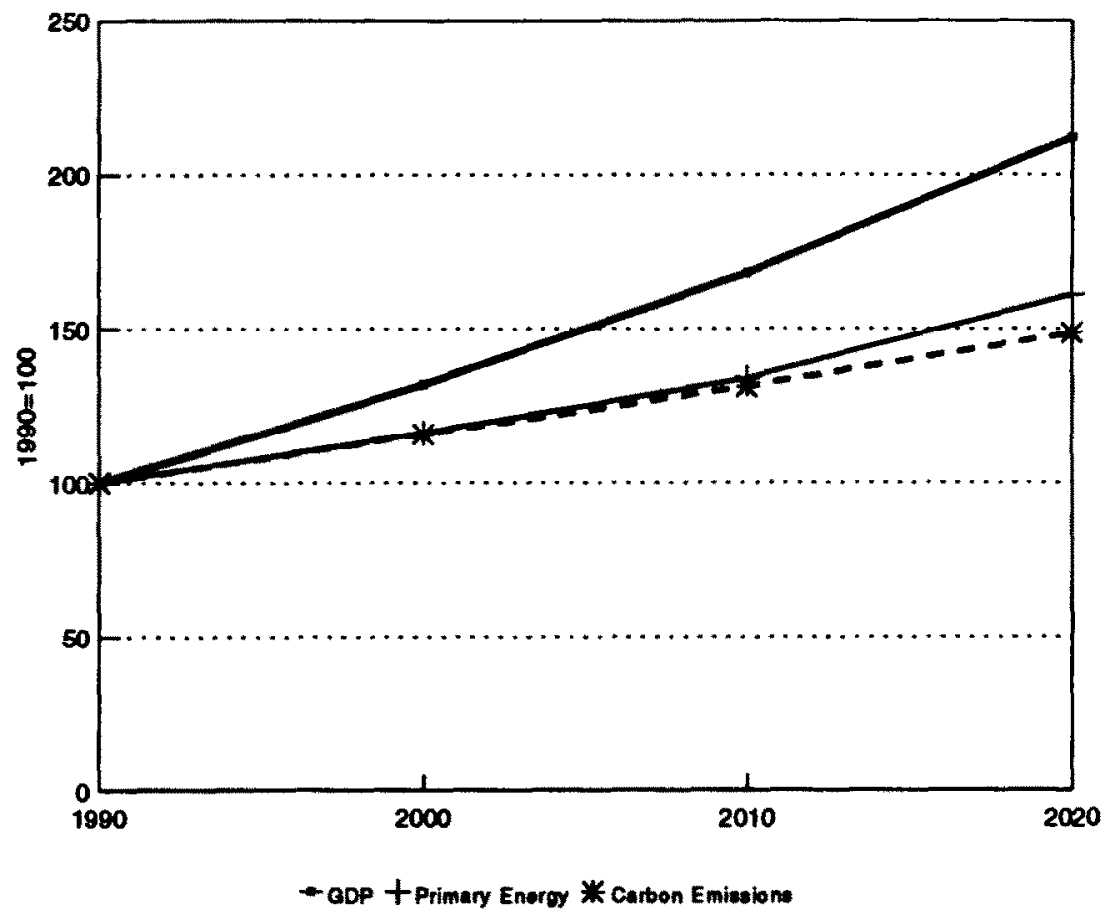

Figure 5. Global aggregates of GDP, primary energy consumption, and carbon emissions; index numbers with $1990=100$. Results of the Global 2100 model with CHALLENGE inputs, Reference case.

the AEEI in the OOECD and ROW regions. These changes are the result of "running Global 2100 backward." That is, for the non-US part of the OECD, the CHALLENGE results could be replicated only by increasing the AEEI values from their original $M-R$ values.

The CHALLENGE poll suggests only two other significant changes in input assumptions: an increase in the role of two carbon-free sources of energy: hydroelectricity and nuclear power.

Global 2100 provides internally consistent projections of international oil prices, world and regional GDP growth, total primary energy consumption, and carbon dioxide emissions. The regional growth rates are, by design, very similar to the CHALLENGE poll results. Figure 5 shows the global aggregates as index numbers based on $1990=100$.

The "decarbonization", that is the decrease of carbon emissions per unit of energy consumed, is generally less pronounced than in the CHALLENGE poll responses. Worldwide, energy-related carbon emissions grow at an average annual rate of $1.3 \%$ (as 


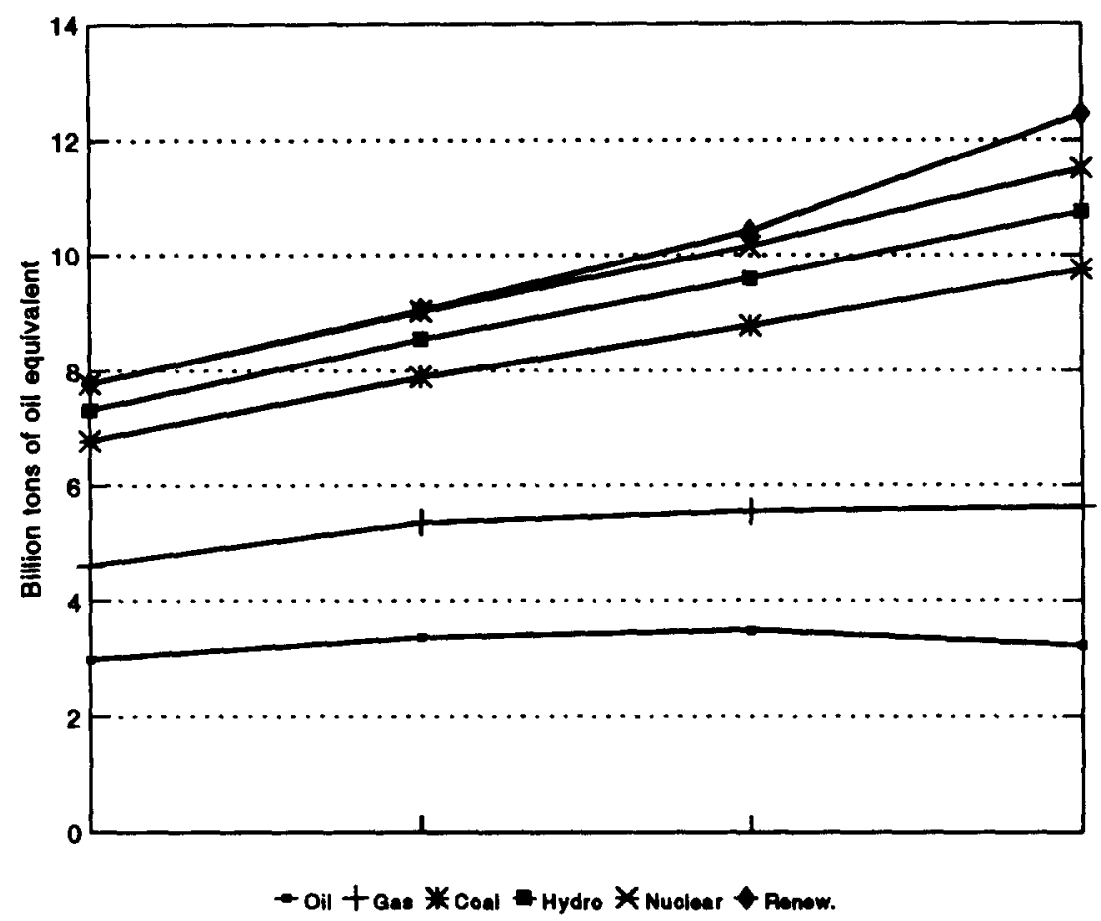

Figure 6. Global primary energy consumption, Global 2100 results with CHALLENGE inputs, Reference case.

compared to the growth rate of primary energy consumption of $1.6 \%$ ). For China, decarbonization is expressed by a $2.5 \%$ growth rate of carbon emissions in comparison to $3.2 \%$ energy consumption growth. The only other region with a significant reduction of the energy system's carbon intensity is OOECD with respective growth rates of $0.6 \%$ (carbon emissions) and $1 \%$ (energy consumption).

In absolute terms, primary energy consumption in the Global 2100 model increases from just below 8 billion tons of oil equivalent (Gtoe) in 1990 to approximately 12.5 Gtoe in 2020 (see Fig.6).

It is instructive to compare the Global 2100 results with the energy-related carbon emission projections of the Intergovernmental Panel of Climate Change (Leggett ${ }^{3}$ ). Among the IPCC scenarios, the highest energy-related carbon emissions occur in the one identified as IS92e. Among other assumptions, this combines: global population growth to 11.3 billion by the year 2100 , high economic growth (an annual average of $3 \%$ worldwide between 1990 and 2100), high fossil fuel availability and the eventual phase-out of nuclear power.

At the other extreme, IPCC scenario IS92e has a $\mathrm{CO}_{2}$ emission path which eventually falls below its 1990 starting level. It assumes that: population grows, then declines by the middle of the next century, reaching 6.4 billion in the year 2100; economic growth is lower (an average annual rate of $1.2 \%$ worldwide between 1990 and 2100 ); and severe constraints on fossil fuel supplies.

Figure 7 compares the two IPCC scenarios with the CHALLENGE projections. On this graph, carbon emissions are given in billion tons of carbon (Gtc; 1 tc $=3.67$ tons of $\mathrm{CO}_{2}$ ). In addition to the two extreme IPCC scenarios, the figure shows the carbon emissions of the Global 2100 Reference case. It also shows an alternative scenario, one in 


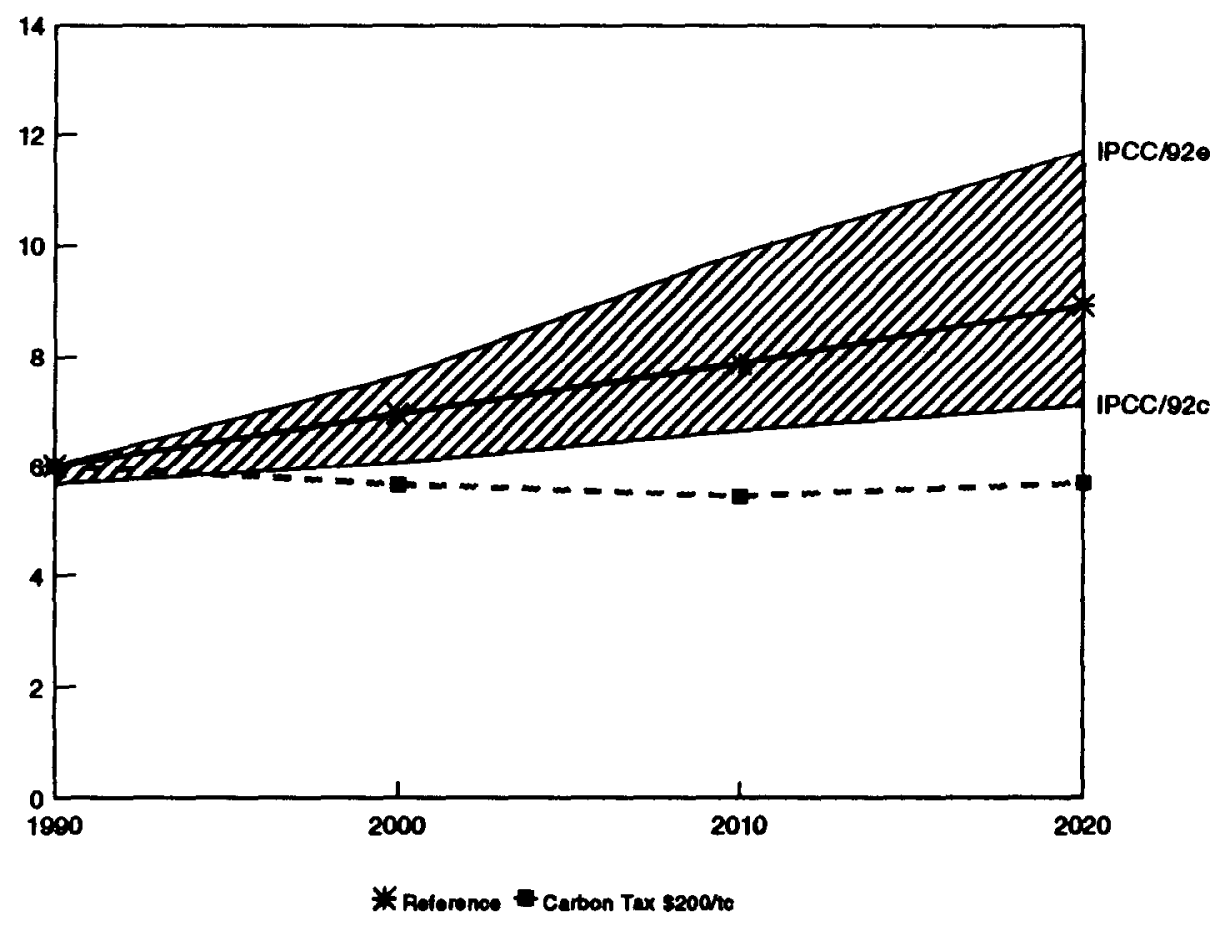

Figure 7. Emission scenarios of IPCC and Global 2100, billion tons of carbon.

which a carbon tax of US\$200 per ton is added to energy prices. If the Reference scenario is really a "do nothing" case, i.e. a scenario in which no special mitigation measures are taken to avoid climate change, then the range spanned by the IPCC scenarios looks significantly higher than the range generated by the preliminary CHALLENGE poll responses, both on the pessimistic and on the optimistic side. The latter is illustrated by the fact that a $\$ 200$ per ton carbon tax could reduce carbon emissions below the lowest IPCC scenario through 2020. It must be added, however, that this tax is not enough to keep carbon emissions below the IS92c scenario during the decades after 2020 .

A further comparison with other global scenarios - the WEC reference scenario (World Energy Council ${ }^{4}$ ) and the scenario by IIASA's ECS group (Nakićenović ${ }^{5}$ ) shows that the growth rates of carbon emissions and primary energy consumption in our Reference scenario are nearly those of the ECS and WEC scenarios, but that GDP growth is slightly higher (see Fig.8).

\subsection{Two Carbon Emission Reduction Scenarios}

In addition to a base case in which there are no carbon emission constraints or any other measures aimed at the reduction of carbon emissions, Global 2100 calculates two alternative cases. In one case, regional carbon emissions are constrained by upper bounds on the appropriate model variables. In the other, a carbon tax of US\$200 per ton of carbon is introduced. The latter case describes the results of a given effort whereas the emission restriction cases identify - through the shadow prices of the carbon constraints - those regions and time periods in which the systems costs of meeting the emission constraints differ from global averages. 


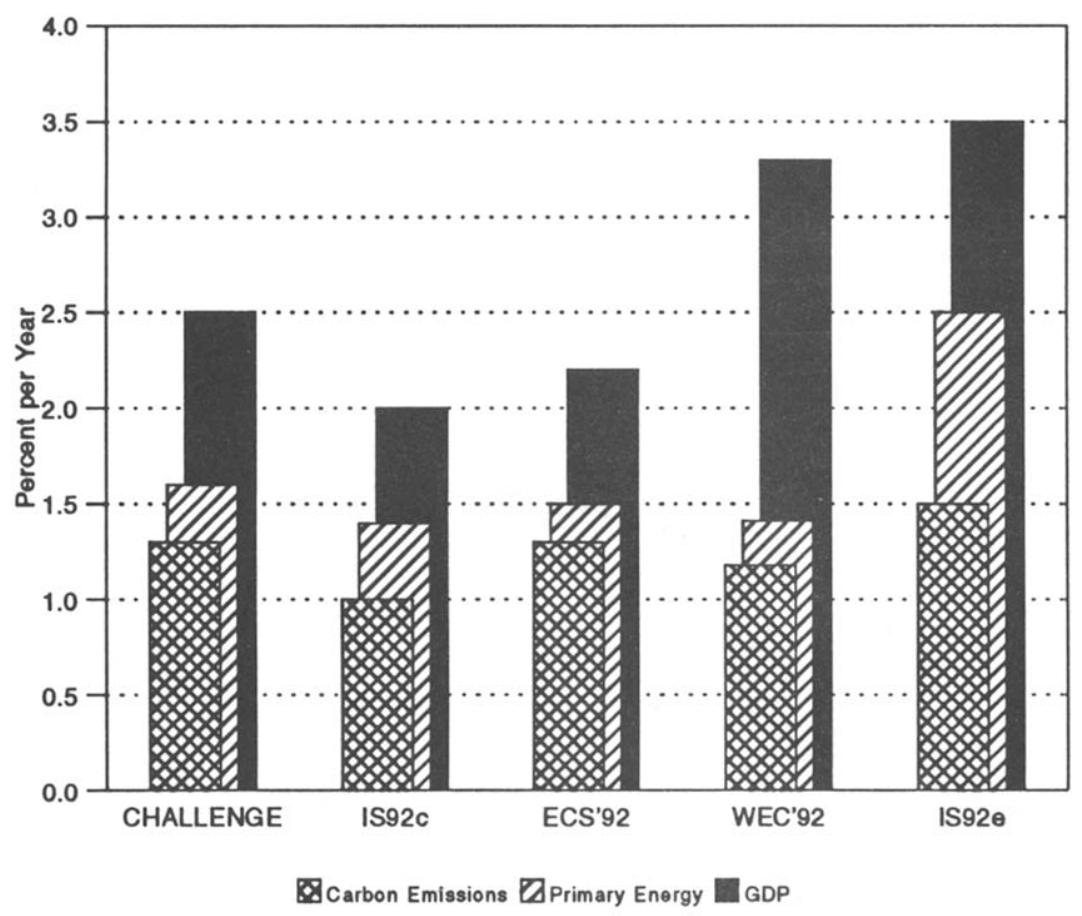

Figure 8. Average annual percent growth rates between 1990 and 2020; carbon emissions, total primary energy consumption, and GDP; results of five global scenarios.

\section{Global Stabilization of Emissions}

In this scenario, the emissions of the industrialized regions (USA, OOECD, and EEFSU) were constrained to $80 \%$ of their 1990 value from 2010 onward. Those of the other world regions (China and ROW) were allowed to increase to $150 \%$ of their 1990 value, also from 2010 onward. For the industrialized regions, the target was stabilization between 1990 and 2000. For the other regions, the value for 2000 was interpolated linearly.

The main result of these scenarios are the marginal costs of these carbon constraints (Fig.9). These values can also be interpreted as a set of carbon taxes imposed separately in each of the five regions. The taxes are designed to achieve a global stabilization of energy-related carbon emissions by the year 2010 , and the revenues from these taxes are recycled domestically. As expected, the less stringent constraints on China and ROW are reflected by much lower carbon taxes than elsewhere in the world. The carbon taxes in the USA and EEFSU exceed $\$ 300$ per ton. The OECD countries outside the USA (the OOECD region) show intermediate values for these tax rates.

\section{A Carbon Tax Scenario}

In order to achieve global economic efficiency, it would be desirable to implement carbon emission charges on a uniform basis between regions. It is straightforward to implement this idea within Global 2100 . To illustrate this concept, a uniform $\$ 200$ per ton carbon tax was superimposed directly upon the Reference case input assumptions. By comparison with other CHALLENGE poll responses, Global 2100 responds with a greater reduction of total primary energy consumption and carbon intensity (recall Fig.4). 


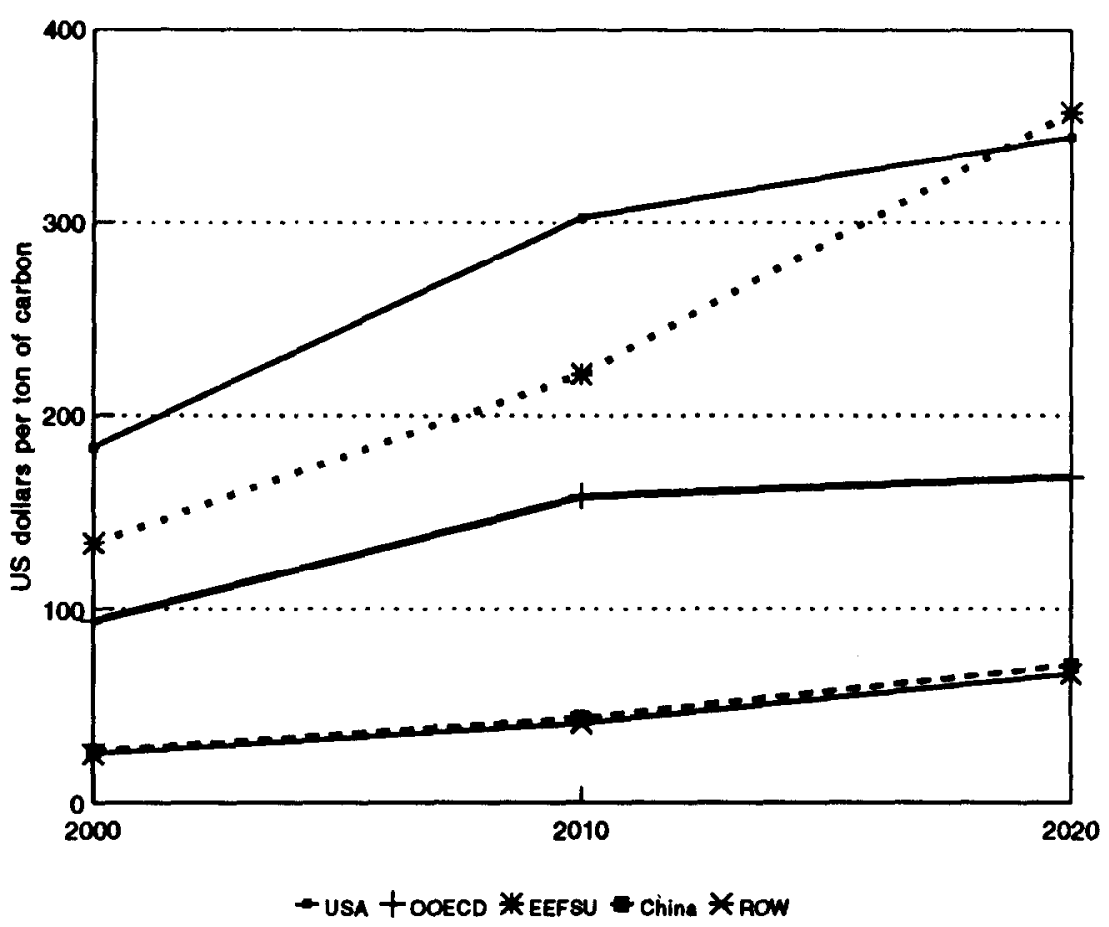

Figure 9. Shadow prices of the carbon emission constraints in the Emission Limits scenario of Global 2100.

Table 4. Annual GDP growth rates for China, in percent, for the Reference and Carbon Tax cases, obtained as outputs of the Global 2100 model.

\begin{tabular}{l|c|c}
\hline Case & $1990-2000$ & $2000-2020$ \\
\hline Reference & 4.93 & 4.36 \\
Carbon Tax & 4.69 & 4.26 \\
\hline
\end{tabular}

Over the horizon through 2020, the effect of such a carbon tax is approximately a global stabilization of carbon emissions at the level of 1990 . Here, we want to show how much such a scenario might cost in terms of deadweight GDP losses. Figure 10 shows that the largest percentage losses could occur in China. The ROW (all other developing countries) would also be major losers from an agreement to institute a uniform global tax. These are rapidly growing regions.

Although the losses may appear large as a percentage of GDP, they would have only a minor impact on long-term percentage GDP growth rates (see Table 4, showing GDP growth rates for China for both the Reference and the Carbon Tax cases). Absolute losses in excess of $4 \%$ (in the year 2020) correspond to a reduction of the growth rate (between 2010 and 2020) of not more than a fraction of one percentage point annually.

These model outputs are only illustrative, and they are not intended to describe a policy that would optimize global costs and benefits of emissions abatement. It is a scenario that is based on preliminary CHALLENGE results. If one were interested in the values of specific output variables, in particular for any of the specific regions, a more 


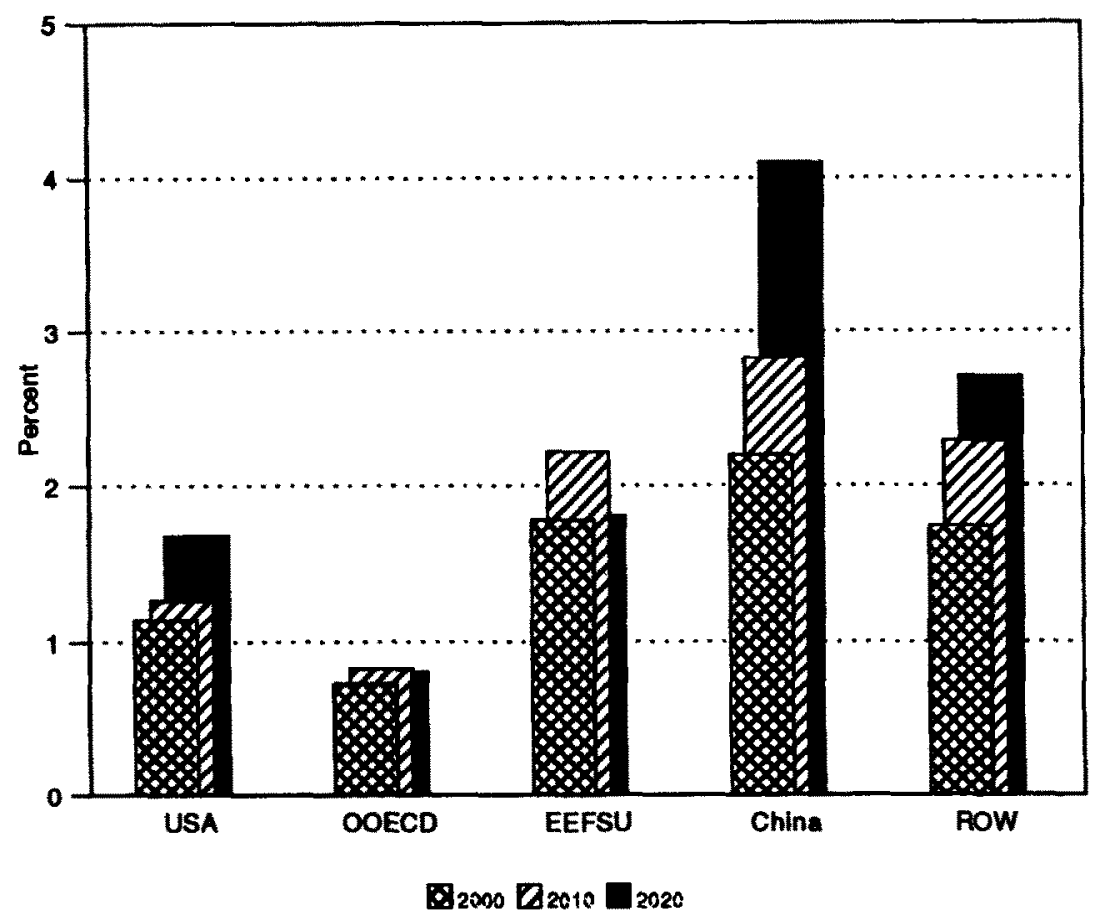

Figure 10. GDP losses relative to the Reference scenario, percent of reference GDP; results of the Carbon Tax case.

comprehensive sensitivity analysis is necessary for those model parameters and inputs that have a major influence upon the variables in question,

According to Global 2100 , introducing a $\$ 200$ per ton carbon tax could reduce global primary energy consumption to just over $10 \mathrm{Gtoe}$ (instead of 12.5) in the year 2020 . The resulting composition of global primary energy supply is shown in Fig.11.

\subsection{A Market-oriented Scenario for Eastern Europe and the Former Soviet Union}

In an economy where energy is subsidized, the real price can be substantially lower than world market prices. This feature can be simulated in Global 2100 through one of the parameters employed in benchmarking the aggregate production function. PNREF represents the domestic price of nonelectric energy during the case year. Thus, by setting PNREF lower than the actual base-year international price, we represent the possibility that an economy was based upon artificially low energy prices. As a consequence, restructuring toward a market orientation of this economy will lead to costless conservation in addition to that induced by the AEEI factor.

As a thought experiment, the EEFSU region of Global 2100 was run with a low reference price for nonelectric energy (PNREF), i.e. US\$1 instead of US\$2 per gigajoule (approximately $\$ 6 /$ boe instead of $\$ 12 /$ boe). Figure 12 shows the results of this case in terms of primary energy consumption. A comparison with the CHALLENGE Reference case is shown in Fig.13. The differences are significant. Total primary energy consumption in the Market-oriented scenario in 2020 is down to 1,830 Mtoe (from 2,180 


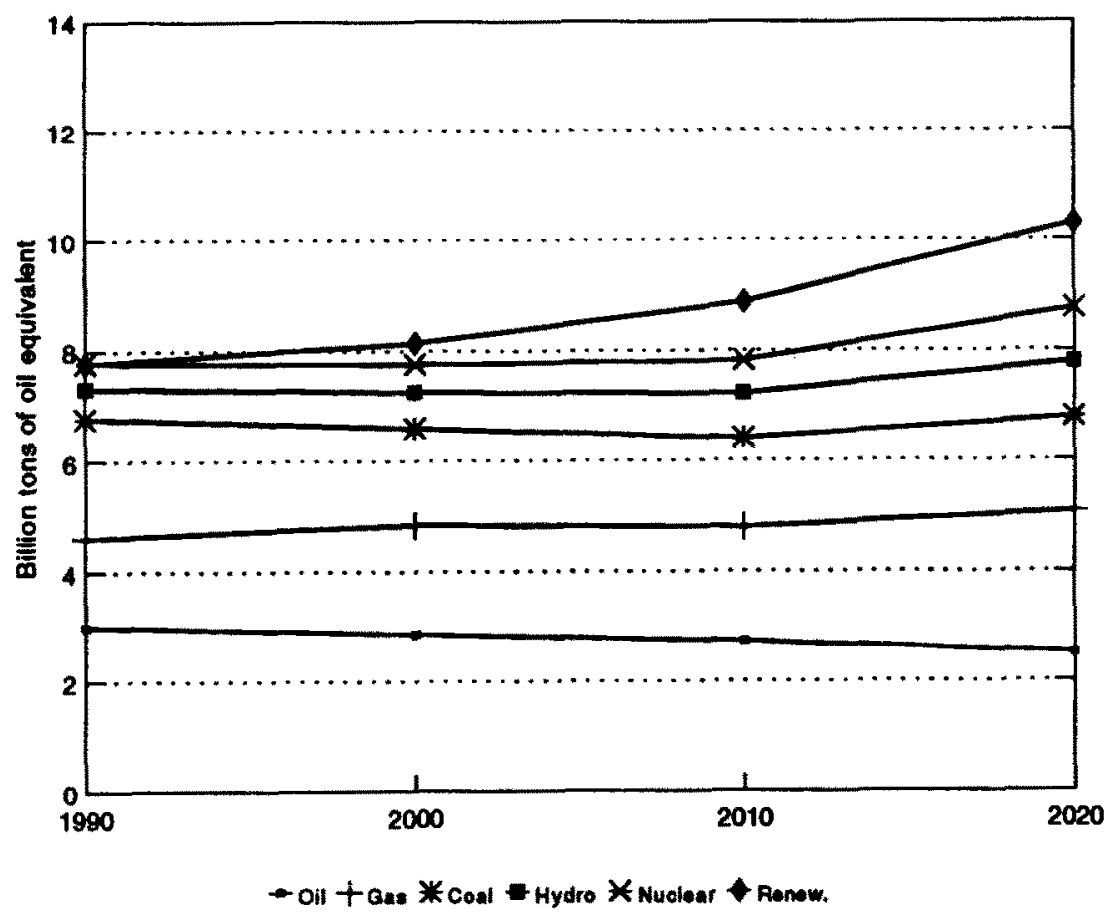

Figure 11. Global primary energy consumption, 1990-2020, Mtoe; results of the Global 2100 model, Carbon Tax case.

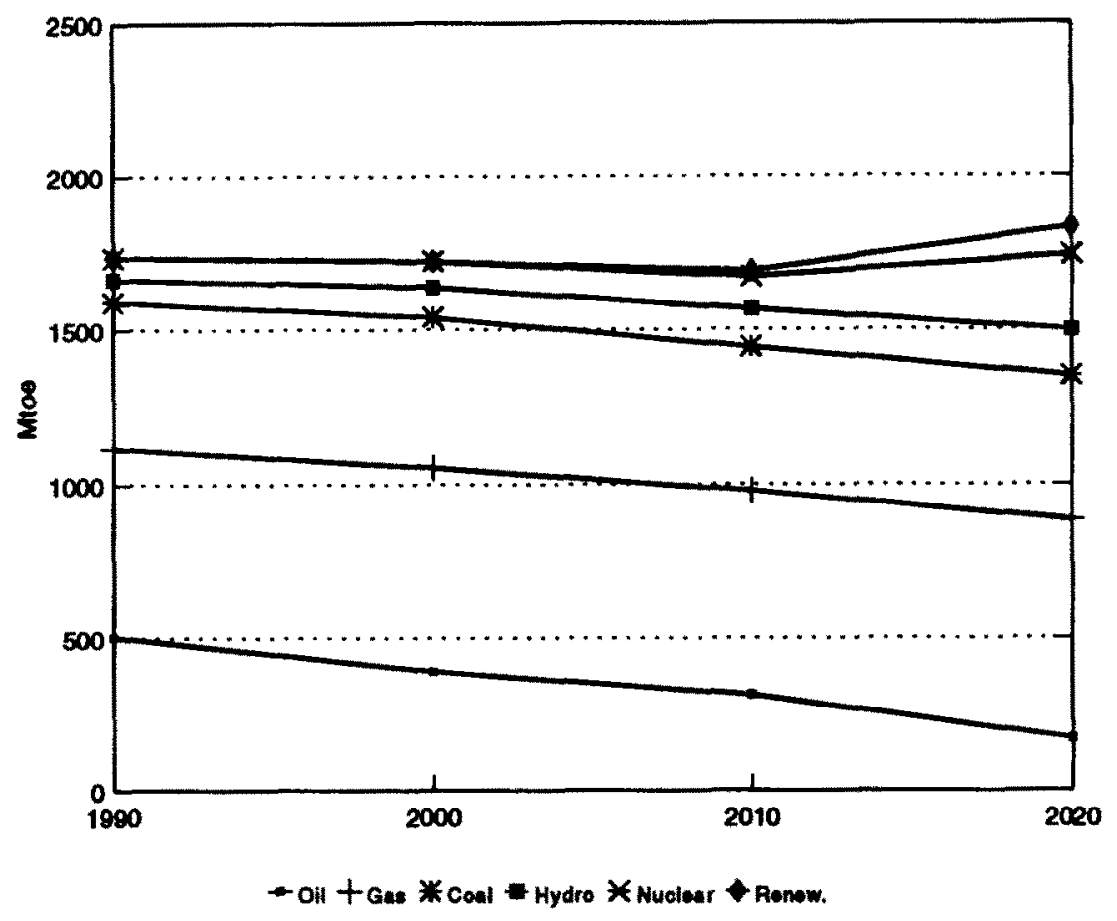

Figure 12. Total primary energy consumption, EEFSU region. "Market-oriented" scenario. 


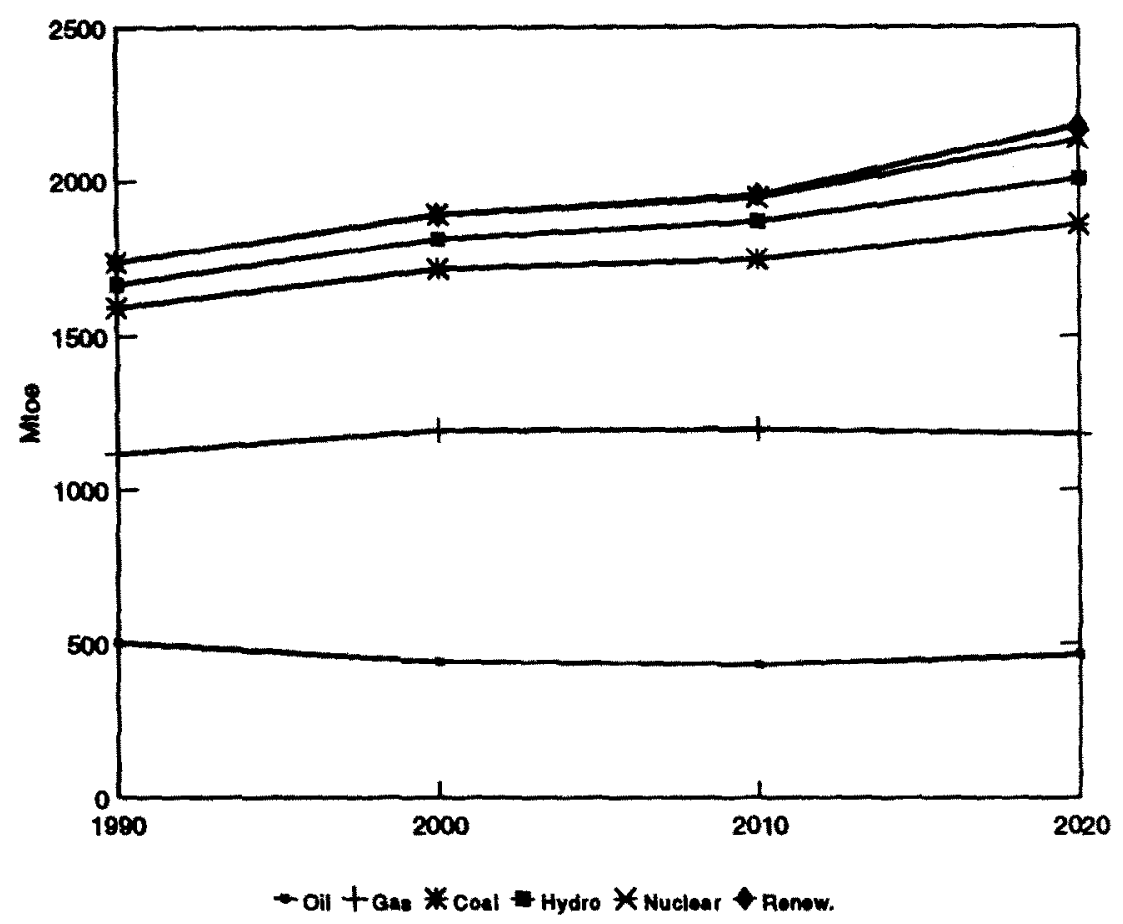

Figure 13. Total primary energy consumption, EEFSU region. CHALLENGE Reference scenario.

Mtoe in the Reference scenario). As expected, much of this drop occurs in the oil sector. With these amounts of additional price-induced conservation, the EEFSU region's carbon emissions decline by $18 \%$ between 1990 and 2020 .

\section{Summary and Outlook}

In the CHALLENGE project, study groups from many countries form an international network. They describe national and global scenarios of carbon emission reductions, and have completed a first round of investigating the consequences of presently prevailing policies and behavior. Preliminary results have led to the formulation of a global carbon emission and energy consumption scenario. The Global 2100 model is employed to ensure controlled comparisons.

Alternative scenarios (one including a tax of US\$200 per ton of carbon and one with constraints on world regional carbon emissions) suggest that global stabilization of energy-related carbon emissions can be achieved at costs in the neighborhood of $2 \%$ of world GDP. It remains to be seen whether realistic policies can lead to such a reduction, whether stabilization of carbon emissions is sufficient to avoid a climatic catastrophe or whether stabilization is an overly ambitious target. The comparison with first and very approximate estimates of damages as a consequence of global warming ( $1 \%$ as the order of magnitude, see Nordhaus ${ }^{6}$ ) would indicate that these costs are too high to justify the benefits. However, in direct response to Nordhaus, Grubb ${ }^{7}$ argues for considering a high uncertainty range of the possible damages, up to $10 \%$ of the global economic output.

Looking at carbon emissions only, our preliminary results suggest that some emission scenarios derived elsewhere, for example by the IPCC, might be higher than necessary 
for a realistic study of policies to avert the risks of adverse global climate change. Members of the CHALLENGE network are refining the national and regional studies, and the formulation of new global scenarios is in progress. The next set of results will be presented at an international meeting to be held at IIASA on 22-24 June, 1993.

\section{Acknowledgments}

The authors are indebted to the U.S. Electric Power Research Institute (EPRI) for partial support of the work presented here. The views presented are solely those of the authors and do not necessarily represent the views of EPRI or the International Institute for Applied Systems Analysis (IIASA) or the other staff members.

\section{References}

1. A.S. Manne, L. Schrattenholzer, and K. Marchant, "The 1991 International Energy Workshop: The Poll Results and a Review of Papers," OPEC Review XV:389-411, OPEC, Vienna (Winter 1991).

2. A.S. Manne and R.G. Richels, Buying Greenhouse Insurance, MIT Press, Cambridge, MA and London, UK (1992).

3. J. Leggett, W.J. Pepper, and R.J. Swart, with contributions by J.A. Edmonds, L.G. Meira Filho, I. Mintzer, M.-X. Wang, and J. Wasson, CLIMATE CHANGE 1992, "The Supplementary Report to the IPCC Scientific Assessment," report prepared for IPCC by Working Group I, Intergovernmental Panel on Climate Change, WMO and UNEP (1992).

4. World Energy Council (WEC), "Energy for Tomorrow's World: The Realities, the Real Options and the Agenda for Achievement," Draft Summary of the Global Report, WEC, London, UK (1992).

5. N. Nakićenović, "Long-term Strategies for Mitigating Global Warming," Energy The International Journal 18, p. 401 (1993).

6. W. Nordhaus, "The Economics of Greenhouse Warming: What Are the Issues?" in "Proceedings of the International Workshop on Costs, Impacts, and Possible Benefits of $\mathrm{CO}_{2}$ Mitigation," International Institute for Applied Systems Analysis, Laxenburg, Austria (1993, in press).

7. M. Grubb, "The Costs of Climate Change: Critical Elements" in "Proceedings of the International Workshop on Costs, Impacts, and Possible Benefits of $\mathrm{CO}_{2}$ Mitigation," International Institute for Applied Systems Analysis, Laxenburg, Austria (1993, in press). 